\title{
Gênero sob ataque: resistências emergentes
}

\section{Gender under Attack: Emerging Resistances}

\author{
Camila Santos Pereira ${ }^{1}$, Anamaria Ladeira Pereira ${ }^{2}$ \\ Eu quero saber quem é que foi o grande otário \\ Que saiu aí falando que o mundo é binário \\ Hein? \\ Linn da Quebrada, 2017.
}

O questionamento, tão provocador quanto necessário, da artista brasileira Linn da Quebrada aborda as divisões binárias de gênero e sua segregadora imposição sobre os corpos. Além da faixa "Pirigoza", da qual um trecho escolhido abre esta resenha, seu álbum Pajubá (2017) recheia-se de contundentes considerações, em forma poética e musicada, às construções coloniais racistas, transfóbicas e machistas de pilares judaico-cristãos. Atacadas pelos mais diversos dispositivos de exclusão, milhares de pessoas possuem suas identidades subalternizadas e, em decorrência de múltiplas violências, precisam enfrentar batalhas diárias para garantir sua humanização e reconhecimento, de modo que possam ter acesso a direitos básicos essenciais, como educação e saúde.

No ano seguinte ao lançamento de Pajubá, estreou para o grande público o documentário peruano Gênero sob Ataque (2018), que também se dedicou a expor escamoteadas hipocrisias ao elucidar os emaranhados, de origens coloniais, responsáveis por conectar os países latino-americanos às novas ondas políticas conservadoras. Ondas, vale ressaltar, com forte patrocínio do Vaticano e de outros interesses econômicos religiosos e não religiosos diversos. Estes visam ao monopólio institucional das decisões, por meio de mecanismos de controle social que pretendem regular as escolhas de cidadãs e cidadãos.

Composto por entrevistas a especialistas, representantes políticos e religiosos, educadoras/es, ativistas, casais e pessoas com individualidades e cotidianos afetados por conservadorismos retrógrados, o filme denuncia sobretudo o moralismo traiçoeiro das elites,

\footnotetext{
${ }^{1}$ Licenciada em Ciências Sociais pela Universidade Federal do Rio Grande do Sul (UFRGS). Mestranda em Educação pela Universidade do Estado do Rio de Janeiro (ProPed/UERJ). Atua no Grupo de Estudos em Gênero, Sexualidade e(m) Interseccionalidades na Educação e(m) Saúde (GENI) e no Grupo de Estudos em Educação e Transgressão (GEETRANS).

${ }^{2}$ Graduada em Pedagogia pela Universidade Federal do Rio de Janeiro (UFRJ). Mestranda em Educação pela Universidade do Estado do Rio de Janeiro (ProPed/UERJ). Atua no Grupo de Estudos em Gênero, Sexualidade e(m) Interseccionalidades na Educação e(m) Saúde (GENI).
} 
pondo em evidência o projeto de poder destas, baseado em sensibilizar o povo com falácias a respeito de ameaças que sequer existem. Nessa lógica de acusação fundamentada, forma-se o retrato das discussões e da polarização, cada vez mais acirrada, enfrentada pelas sociedades latino-americanas, assaltadas, por um lado, pela desigualdade social crescente e, por outro, pela politização, cada vez mais obsoleta, dos religiosos. Com a narração do diretor, Jerónimo Centurión, reportagens são exibidas para situar e explanar as distintas, mas similares, disputas em relação às discussões sobre equidade de gênero, população LGBTTQI+ e direitos sexuais e reprodutivos.

\section{Quem tem medo da palavra gênero?}

A expressão “ideologia de gênero", estrategicamente usada para denominar/demonizar boa parte dos direitos humanos alcançados por mulheres e pessoas LGBTTQI+, caracteriza-se como munição, através da qual organizações religiosas e tradicionalistas desautorizam os estudos feministas, principalmente na última década. Por intermédio de uma aliança entre os setores mais conservadores das igrejas católica e evangélica, unidos em prol de uma causa comum, uma nova era de distorções das contestações dos movimentos sociais e acadêmicos surge com extrema força e propagação virtual alarmante. A deslegitimação contínua da ciência não tem sido inibida com o acesso rápido à informação e com o aumento das taxas de escolarização. Tais avanços, no entanto, se aliados ao desenvolvimento do pensamento crítico mostram-se fundamentais para interpelar os discursos assimilados pelas diferentes gerações contemporâneas. Discursos baseados em argumentos sem conexões com a realidade, na intenção apenas de perpetuar como válida uma única forma de vivência, subjugam mulheres e invisibilizam identidades de gênero e orientações sexuais inconformes com as estreitas margens da normalidade imposta. $\mathrm{O}$ filme denuncia a estratégia de grupos religiosos que contam com o apoio de uma população numerosa que legitima semelhantes despautérios e apoiam a formação de estudantes que, em vez de questionar, acatem, guiados pela fé. Nada pode ser mais perigoso para os propósitos opressores e antidemocráticos do que uma educação laica e livre.

Nesse sentido, a escola torna-se o centro dos embates. De um lado, representantes de um mundo reacionário, permeado pelos interesses de entidades cujos líderes específicos concentram boa parte da renda que deveria ser melhor distribuída entre a população como um todo; de outro, um universo povoado por defensoras e defensores de abordagens realmente questionadoras. Esses questionamentos são imprescindíveis para enfrentar, desde o ambiente escolar da mais tenra infância, o machismo e a misoginia, responsáveis por altos índices de 
feminicídio e pelas diversas formas de violência contra as mulheres e meninas e contra a população LGBTTQI+ na América Latina. O Brasil, por exemplo, ocupa a quinta posição na classificação dos países com as maiores taxas de assassinatos de mulheres no mundo. Apenas "El Salvador, Colômbia, Guatemala (latino-americanos) e a Federação Russa exibem taxas superiores às do Brasil" (APG, 2015). A esse dado soma-se o fato de que, em 2015, pôde-se observar investidas, em todo território nacional, de exclusão total do termo "gênero" dos Planos nacionais, estaduais e municipais de educação (CARVALHO, 2015). Até mesmo disciplinas como português e biologia foram afetadas, ainda que, em sua grande maioria, a menção à palavra não estivesse relacionada com as construções sociais relativas aos papéis de gênero que mulheres, homens e outres desenvolvem. Tal perseguição desenfreada advém do errôneo entendimento de que "a identidade de gênero causa a orientação sexual ou que a sexualidade tem necessariamente como referência uma prévia identidade de gênero" (BUTLER, 2009, p. 6). Como essa crença conservadora provoca segregações, sofrimentos e desigualdades, há forte urgência em promover discussões embasadas na leitura teórica de pensadoras e pensadores, como Judith Butler, a fim de desconstruir essas disparidades contemporâneas.

\section{Sobre o processo colonizador que nos conecta}

Ao atravessar as fronteiras e retratar eventos singulares em Costa Rica, Peru, Colômbia e Brasil, o documentário possibilita analisar as marchas religiosas, a oposição ao casamento igualitário, o descarte de planos de educação com propostas mais progressistas referentes às diversas vivências de gênero e sexualidade e as respostas violentas contra acadêmicos e ativistas que defendem as pautas menosprezadas pelo pensamento dominante. $\mathrm{O}$ processo colonizador conecta as histórias dos quatro países latino-americanos, entretanto, a história comum compartilhada não evita que os acordos econômicos ainda sejam as trocas mais relevantes entre essas nações. Academicamente, o trânsito teórico, sobretudo dos estudos descoloniais e decoloniais, tem aumentado consideravelmente as construções de projetos sociais que inauguram ou estabelecem diálogos entre diferentes culturas e trajetórias. No intuito de compreender melhor os retrocessos e a disseminação do ódio contra populações marginalizadas, para poder combatê-los, faz-se indispensável atentar para o papel da religião na colonização do continente.

Assim, à medida que o cristianismo tornou-se o instrumento mais poderoso da missão de transformação, a normatividade, que conectava gênero e 
civilização, concentrou-se no apagamento das práticas comunitárias ecológicas, saberes de cultivo, de tecelagem, dos cosmos, e não somente na mudança e no controle de práticas reprodutivas e sexuais (LUGONES, 2014, p. 938).

Assistimos, no média-metragem, não apenas uma onda conservadora e seu estabelecimento, como também os atravessamentos que silenciaram e perseguiram modos múltiplos de estar no mundo antes da implantação desse sistema opressor. Sendo assim, podemos salientar que "gênero é uma imposição colonial” (LUGONES, 2014, p. 942).

\section{Os perigos da autonomia}

Em diferentes recortes da produção cinematográfica, líderes religiosos e familiares de diferentes gerações e origens manifestam-se com declarações contestatórias bastante parecidas, claramente em desacordo com uma suposta proposta de ensino, alegando que suas filhas e filhos aprenderiam, na escola, a escolher quem querem ser. Tal ideia, relacionada diretamente com o que se entende a respeito da abertura à interlocução com estudantes sobre identidades de gênero e orientação sexual, possui uma raiz distorcida das proposições e objetivos originais. Não se trata de ensinar uma pessoa a identificar-se com um gênero e/ou uma sexualidade diferentes daqueles com os quais se reconhece (como se tal "ensinamento" fosse possível!), mas de saber lidar com as questões invisibilizadas daquelas e daqueles compreendidos como dissidentes dentro das lógicas heterocisnormativas. Negar, por exemplo, a existência da homossexualidade passa a informação de que se trata de algo que não deveria existir e, ao mesmo tempo, um assunto que não merece se misturar aos realmente importantes, trabalhados em sala de aula. Tal silenciamento estimula as 'gozações' e os ‘insultos' dos recreios e dos jogos, fazendo com que, deste modo, “jovens gays e lésbicas só possam se reconhecer como desviantes, indesejados ou ridículos" (LOURO, 1997, p. 68).

Um dos resultados dos projetos que envolvem abordar gênero e sexualidade na escola pode, sim, ser a autonomia e a multiplicação de maneiras de se conhecer e perceber as experiências individuais. Por que o autoconhecimento seria uma ameaça? Desafiar os padrões da heterossexualidade, da cisgeneridade e da branquitude expressa uma resistência que tem o poder de movimentar as estruturas das sociedades capitalistas neoliberais contemporâneas. Abalar esses pilares faz parte de (re)conhecer as histórias latino-americanas que foram espoliadas. Contudo, a abordagem dos enunciados acerca da representatividade requer cautela, visto que tais discursos, frequentemente lidos como reivindicatórios, costumam ser revestidos 
por motivos comerciais e de interesses econômicos que acabam reinventando moldes. Trabalhar com essas realidades a partir de olhares interseccionais e da epistemologia feminista descolonial/decolonial permite a identificação da historicidade colonizadora das práticas cotidianas, tendo em vista que a interseccionalidade destaca a "inseparabilidade estrutural do racismo, capitalismo e cisheteropatriarcado" (AKOTIRENE, 2018, p. 14).

O engajamento da população peruana na campanha "Con mis hijos no te metas" provoca assombro, pois demonstra um imenso empenho em recusar atividades desmistificadoras de comportamentos, legitimando, por exemplo, a violência sexual. A base desse conflito está na crença de que a homossexualidade seria ensinada em sala de aula e que docentes de sexualidades dissidentes abusariam de estudantes. Essas lógicas, carregadas de preconceitos arcaicos, são, no entanto, legitimadas por iniciativas religiosas que buscam esconder o fato de que grande parte dos casos de abusos sexuais de meninos e meninas acontece em suas próprias casas, e não nas escolas, sendo seus parentes os abusadores, e não profissionais de estabelecimentos educativos. Segundo dados do Atlas da Violência de 2018, produzidos pelo Instituto de Pesquisa Econômica Aplicada (IPEA) e pelo Fórum Brasileiro de Segurança Pública (FBSP), 68\% dos registros de estupros, no sistema de saúde, se referem a estupro de menores de idade e, aproximadamente, $60 \%$ são cometidos por amigos, conhecidos da família ou familiares próximos, como pais, mães, padrastos e irmãos (ATLAS DA VIOLÊNCIA, 2018, p. 4).

Os diálogos sobre uma aprendizagem acerca desses tópicos poderiam abrir um espaço significativo para o reconhecimento e denúncia desses abusos, porém são tolhidos a partir de parâmetros retrógrados. Nesse campo de disputas de poder, projetos sociais comprometidos com a equidade social são atacados por diferentes fontes e lutam para se manter em produção.

O documentário resenhado explicita que a expressão “ideologia de gênero" serve apenas para que grupos conservadores e religiosos criem entraves para o debate sobre diversidade sexual e identidade de gênero. Esse é um tema caro para governantes com base eleitoral fortemente evangélica e católica. Sobretudo no caso brasileiro, com a crise acentuada por sua inépcia em governar, aquele que ocupa o cargo mais alto do legislativo, atualmente, encontra, nessas pautas, um meio para levantar sua, cada vez mais aniquilada, popularidade. Seus aliados não têm escrúpulos e simplesmente descontextualizam propostas que visam à igualdade e as tratam embasados numa falsa moral, desatando a ira e o temor em boa parte da população.

Configura-se, assim, um retrato atual desolador, em que há a necessidade constante de seguir lutando para desmantelar a estrutura que impõe como únicas referências pertinentes as que se enquadrem na heterocisnormatividade branca. Gênero sob Ataque, premiado em 2018 
como o Melhor Filme sobre Direitos Humanos do Alto Comissariado das Nações Unidas, somase à luta por oportunidades e direitos semelhantes para todas as pessoas, independentemente de sua orientação sexual e identidade de gênero.

\section{Referências bibliográficas}

AKOTIRENE, Carla. O que é interseccionalidade?. Belo Horizonte: Letramento, 2018. 143p.

APG. Brasil é o $5^{\circ}$ no ranking de homicídios de mulheres. Agência Patrícia Galvão, 2015. Disponível em: https://dossies.agenciapatriciagalvao.org.br/feminicidio/capitulos/qual-adimensao-do-problema-no-brasil/\#brasil-e-o-5o-no-ranking-de-homicidios-de-mulheres. Acesso em: 14 maio 2020.

ATLAS DA VIOLÊNCIA 2018. Rio de Janeiro: Ipea/FBSP. jun. 2018. Disponível em: http://www.ipea.gov.br/portal/index.php?option=com_content\&view=article\&id=33410\&Itemid= 432. Acesso em: 16 jun. 2020.

BUTLER, Judith. Desdiagnosticando o gênero. Physis: Revista de Saúde Coletiva, Rio de Janeiro, v. 19, p. 95-126, 2009.

CARVALHO, Milena. Exclusão de gênero do Plano Nacional de Educação é retrocesso, diz educador. Último Segundo, 26 dez. 2015. Disponível em: https://ultimosegundo.ig.com.br/educacao/2015-12-26/exclusao-de-genero-do-plano-nacional-deeducacao-e-retrocesso-diz-educador.html. Acesso em: 14 maio 2020.

GÊNERO SOB ATAQUE. Direção: Jerónimo Centurión. Produtora: Erika Miranda. Peru: Clacai, 2018. 1 vídeo (70 min.). Disponível em: https://www.youtube.com/watch?v=Aj3St_zUM7M. Acesso em: 14 maio 2020.

LOURO, Guacira Lopes. Gênero, sexualidade e educação: uma perspectiva pós-estruturalista. Petrópolis: Vozes, 1997. 179p.

LUGONES, María. Rumo a um feminismo descolonial. Estudos Feministas, Florianópolis, v. 22, n. 3, p. 935-952, jan. 2014.

QUEBRADA, Linn da. Pajubá, Direção artística: Mc Linn da Quebrada, Direção musical: BadSista, 2017. 1 CD. Gravado: 08/2017 no Estúdio YB Music, São Paulo/SP. 